\title{
Research on the Setting of "Problem" in the Teaching of Post
}

\section{Education}

\author{
Liu Zhongmin*, \\ Wuhan Mechanical College, \\ Wuhan, 430075, China \\ * Corresponding author. E-mail: 1137645276@qq.com
}

\author{
Zhou Zelong, \\ Wuhan Mechanical College, \\ Wuhan, 430075, China
}

\author{
Tu Shanchao \\ Wuhan Mechanical College, \\ Wuhan, 430075, China
}

\begin{abstract}
Under the current new situation, the core principle of the reform of the education and teaching in the military academies is the "problem center". In the center of the teaching mode, the "problem" is the core of teaching, the teaching process is carried out around the "problem". Based on the analysis of the status of "problem" problem centered teaching mode based on the proposed worked in education and teaching, setting principles and strategies, on the teaching reform of the post education has a certain guiding significance.
\end{abstract}

Key words-Post education, Problem center, Teaching reform

\section{INTRODUCTION}

"The problem is the center of the teaching mode" (problem based learning, PBL) is 1969 barrows, an American professor of Neurology at McMaster University in Toronto, Canada, presented a problem solving teaching method. The characteristics of this kind of teaching mode is to put the "problem" in teaching the core position, "" through the whole process of teaching, the teacher to the problem centered teaching, students taking the question as the starting point to explore the knowledge to cultivate students creative spirit and ability of the teaching objectives. This kind of teaching mode focus on students to acquire knowledge and does not emphasize the students to acquire knowledge, advocate students practical application of imparting knowledge, emphasize the development of students' thinking is the core of the learning ability, innovation ability and problem solving ability. In the office of education and teaching carried out in "problems" as the center of teaching mode, to cultivate high-quality military personnel of a new type, to advance the military academy post education has very important significance.

Socrates once said: "education is not to instill, but to ignite the flame". In the problem centered teaching mode, the "problem" is the seed of the fire. Problem is the bridge and link to realize the teaching and learning, is a teacher of teaching goal, teaching content and teaching process effectively grasp the tool.

The core of the reform of college classroom teaching is cultivate students creative spirit and ability, is to change the traditional rote, mechanical training, so as to ignore the students with their own feelings and experience of teaching mode, cultivating students dare to explore, diligent in thinking, willing to learn, attention to students to explore knowledge and learning methods of training, to stimulate the students found the problem, proposed the question, the analysis question and problem solving ability. Problem centered teaching mode will be the core problem in the teaching position, build feelings 
and learning platform for students. Students find problems, analyze problems and solve the problem of the whole process, that is, the process of learning experience. At the same time, teachers in setting, guide problem is to guide the students to feel and experience, consciously open mind, self development process. So the problem is that students feel and open the door of the mind.

Creation begins with the problem, there is a problem, can think, there is thinking, problem solving methods, in order to find the possibility of independent thinking. To "problems" as the center to carry out the teaching process, students from the discovery of the problem, analysis problem, and to solve the problem in the last, is to stimulate the creative process. Both on the concept of deep research and discussion, or feeling of experience and discover; both on theoretical problems deep design and research applications or to practice experience and try to are created by students in teacher good situation in the initiative to complete. So, in a good situation, the creativity of the students can be well inspired, the problem is to stimulate the motivation of students creativity.

According to the principle of education, the most effective learning is to construct knowledge system actively. The problem is to stimulate students to learn, and consciously build a bridge of knowledge. Knowledge itself is dynamic and subjective initiative, students in thinking and solving problems, due to an individual's background, see the different attitude and emotion, to solve the problem in different ways, which will come to different results. In the problem teaching method, promote the problem of bad structure, that is, there is no standard answer to the question. This can stimulate students' divergent thinking, according to analysis and solve the problem of their own experience and feelings, so that students can construct their own knowledge system. As the American physicist Richard feman once said, the problem of meaning and value can be distinguished and unanswered questions may still be profound and significant. Therefore, the process of learning is the process of knowledge construction. The problem is that the students in the learning process and knowledge of the dynamic relationship between the link.

\section{The basic principles of "problems" in the teaching of post - Service Education}

Problem centered teaching mode to cultivate the students' creation ability, independent learning ability, cooperation and communication ability to provide a good platform for the implementation. In "problems" teaching mode of the centre, the "problem" is core of course dominated, set reasonable and valuable problem is to ensure effective problem teaching target. Therefore, the set of issues should follow the following principles:

The setting of the problem should be scientific. Serving education students are from the first line of troops, has a wealth of post experience and practical experience. Therefore, the teaching content and the teaching object of the post education teaching are different from the teaching of undergraduate education.

So the teacher questions must according to serve education course content and student characteristics of, otherwise it is impossible to achieve the teaching goal. Set the question scientifically is a fundamental problem in the teaching mode of the center ring, and always go through the whole teaching process. Teachers should know the knowledge foundation of the students and fully understand and master the curriculum standards and the teaching content, dig textbook contains the knowledge and skills of value and emotional value, using the knowledge as a problem situation material, scientific and rational design good at every subject.

The setting of the problem has to be pointed. Professional education students and other students in the knowledge base and practical experience and different training objectives are different. For the education of the students, the problem is set to have the direction of. Teachers should focus on the new revolution in military affairs and military struggle preparation under the condition of great leap forward development of the construction of combat troops need to solve focal point and difficult point and hotspot issues, "colleges and 
universities closer to the troops, troops to combat focused" principles as a guide, adhere to the principle of "close to the troops and close to real war", closely students troops real work demand set, ensure that the "problem" has directivity.

The setting of the problem should have a gradient. Office of education students knowledge base uneven, so different knowledge base of students understanding of the problem and master degree is also different. Also in accordance with the rules of human cognition, people's understanding of the problem is often from the surface to the essence, from shallow into the deep layer of the progressive. So the trainers in setting up the problem to a reasonable level and gradient, from easy to difficult, from perceptual to rational, from phenomenon to essence, the students thinking gradually lead to a new height. So as to stimulate students' interest in learning, enhance students' self-confidence and inspire students to think actively and initiatively, stimulate the students explore issues of internal driving force.

The setting of the problem should have the leading edge. The goal of serving education is to train the applied military personnel to meet the needs of the military post. The changing international situation and the world pattern, the attendant is the security situation in the country is faced with new opportunities and challenges, the construction of combat troops will meet new problems. Therefore, in office of education and teaching, teachers should the new situation and new problems faced by the countries concerned, combined with advanced the theory of revolution in military affairs, in-depth analysis of the contradictions and problems encountered in construction of combat troops, focus on the cultivation of military talents demand has set up front. Frontier problems often have challenge, can stimulate the students' learning initiative and enthusiasm, to promote students thinking and synchronous development, achieve professional education to lead the construction of the army's battle effectiveness objective.

\section{The strategy of setting up "problem" in the teaching of post education}

In the process of teaching, the key is the setting of the problem situation. A good problem situation, make the teaching content with novelty, so that students have the curiosity and thirst for knowledge, effectively stimulate the students motivation to explore, to cultivate the ability of students to ask questions. Einstein once said: "it is more important to put forward a problem than to solve a problem". The latter is only the process of discovery and experimentation, and the key point to find the problem is to put forward the problem. Therefore, whether the problem is set properly or not is directly related to the effect of teaching objectives.

Problem centered teaching mode, the "problem" is the center of teaching is the core, through the problem to achieve knowledge and ability, process and method, sensibility, attitude and value view of the three-dimensional teaching objectives. The teaching goal of serving education is to improve students' ability of post office. In office of education and teaching, teachers set must be closely linked to the serving the teaching goal, to achieve the teaching goal, teaching content, students' cognitive ability and serving requirements of integration. In the teaching process, teachers should around students post demand, and needed to be solved in the current construction of combat troops practical problems, reasonable design can be close to the troops, close to the actual, can stimulate students' interest in learning. The teacher through the setup of the problem, for students to provide way of thinking. By traction students to think, to enable students to step by step the research starting from the starting point of the problem, in the process of problem solving training identify problems, ask questions and solve problems. In addition, in education and teaching professional problem set, but also consider the trainee's level of knowledge and ability, not the problem set is too large or too small. Problem is too large, the scope of a wide, students is difficult to grasp the focus, unable to stimulate students to explore the interest in learning; small problem, for students in 
terms of no challenge, I feel there is no research is necessary, can not stimulate the enthusiasm of the students to explore and enthusiasm of learning. Therefore, the setting of the problem to in accordance with the objectives of the teaching requirements for students's post office needs, according to the actual situation of students, set reasonable.

Learning process is a cognitive process, the cognitive process of the students divided into exploration, research and application, in mental performance for observation, thinking and migration. Education should respect the human cognitive rules, if you don't pay attention to cognitive rules and only in the way of efforts should put the cart before the horse, learning effect is poor. Serving education students from different grass-roots units, with their goal to learn, there is a strong creative spirit and desire for knowledge. Students in the learning process and need to the perceptual knowledge rise to rational knowledge, the rational thinking of achievements for the army organized the implementation ability of commanding, training and management, in order to improve the position of the Corps of cadets working ability. So the trainers in the "problem" as the center to carry out teaching, starting from the student's cognition rule, in the students have the knowledge based, in accordance with the laws of the cognitive settings, guide the students from the known to discover the unknown, to establish their own knowledge system; so that students from to ask questions of the perceptual knowledge of, and in the process of thinking and exploring, and gradually increased to the problem of rational understanding, so as to nurture students identify problems, ask questions and solve problems. Students in the process of problem solving, their existing knowledge sublimation and reconstruction, set up their own new knowledge system, update the students knowledge, enhance the learner's level of knowledge and ability.

Knowledge is not isolated, but interrelated. On knowledge learning process, is the use of the intrinsic link between the old and new knowledge, as a bridge, the establishment of new knowledge system based on existing knowledge. Professional education students have some basic knowledge and practice experience. Therefore, faculty members in the "problem" as the center to carry out teaching to the students already have the knowledge based settings, the "problem" for students to show the intrinsic link between the old and new knowledge, for students to provide a thinking path and the question of space with the help of "problem", so as to stimulate students to think of the engine, let the students to have a more in-depth research and exploration problems, and we can find the problems, ask questions, analyze problems, the ultimate solution to the problem. Students in the process of problem solving, through exchanges and cooperation and explore, summarize inherent logical connection between old and new knowledge, so as to improve comprehensive ability of the students knowledge transfer. Professional education must not only update the students knowledge, but also cultivate students' theoretical with practical ability, and then improve the students ability to post office. Therefore, teachers should pay close attention to the current hot issue, closely follow the development of the times, close to the reality of the army, closely linked to the needs of the job, through cooperation and exchange students to study, collision of ideas, we can find the answer, the ideas and methods to learn to solve problems, in learning knowledge while improving comprehensive ability and quality. In the office of education and teaching, teachers should help students practice experience, find a difficult and hot problem in construction of combat troops, the use of traction as, in resonance in thought and method of promoting to help students to complete the construction of new knowledge system.

\section{Conclusion}

"Taking the question as center" teaching mode is a problem solving model, take the teacher as the leadership, students as the main body, the key lies in the problem set. In office of education and teaching, problem sets must conform to the requirements of the student's knowledge 
background and post, pays great attention from the different angle setting, try to reflect the era characteristic and frontier, directivity, avoid the teacher put forward the problem is too large or too small, so that students feel not a marginal or no inquiry enthusiasm. The teacher to continuous optimization problems, to the problem as the center to carry out teaching, expand the breadth and depth of the students' thinking through a clever set of problems, with questions to guide students to explore and summarize, so as to improve the classroom teaching effect.

\section{Acknowledgement}

This project is supported by Teaching Reform Funding of Wuhan Mechanical Technology College.

\section{References}

[1] Zhang Zhangran. Problems of philosophy research [M]. Beijing: People's publishing house, 2005: 52

[2] Chen Qingyun. Research and application of the teaching mode of problem center [J]. basic education, 2011,8 (3): 35-42. 